\title{
Extending activity-based models of travel demand to represent activity-travel behaviour of children: some descriptive results
}

\author{
T. Arentze \& H. Timmermans \\ Eindhoven University of Technology, Urban Planning Group, \\ PO Box 513, 5600 MB Eindhoven, The Netherlands
}

\begin{abstract}
This paper reports some descriptive findings of activity-travel behaviour of children. Summary statistics are compared with those pertaining to household heads. Significant differences are found between children and household heads on virtually all indicators. It suggests that activity-based models of transport demand need to systematically include the behaviour of children and their interdependencies with activity-travel behaviour of other household members.
\end{abstract}

Keywords: activity-travel behaviour, children, household heads.

\section{Introduction}

Activity-based models of transport demand have truly matured over the last decade. Several fully operational models have become available lately [1-6]. In contrast to traditional trip-based and tour-based models, these models allow transport planners and policy makers to consider a wider range of factors in scenarios (e.g., temporal factors). Furthermore, they are also able to predict activity-rescheduling behaviour of individuals/households in response to policyinduced or autonomous changes in space-time settings.

In this paper we explore and propose an extension of activity-scheduling models to address one particular shortcoming of current approaches. Current activity-scheduling models focus on adult members of households (i.e. household heads) and do not represent the schedules of children or other persons living in households explicitly. This omission does not only reduce the sensitivity and power of the models, but also means that forecasts of travel demands cannot be readily made for an entire population. On the other hand, 
some activity-travel surveys in many countries include the activity diaries of all members of a household (or from a particular age such as 12 years and older).

Against this background, the purpose of the present paper is to assess impacts that activity schedules of children have on travel demands in a (national) population. Based on an existing dataset (the MON survey) we analyse activitytravel schedules of children of a large national sample of households (approximately, 30.000 households) and investigate the significance of incorporating this behaviour in activity-based models. The paper is structured as follows. First, we briefly review existing work on activity-travel schedules of children. Next, we describe the results of an analysis of the MON data with the purpose first to reveal general patterns of behaviour and next to assess the relative contribution of children to aggregate travel demands of the (Dutch) population. Finally, we conclude the paper with a discussion of major conclusions.

\section{Related work}

McDonald [7] found based on a National Household Travel Survey in the US context that children's travel behaviour is similar to adults in terms of transport mode (the percentage of travel being made in a private vehicle), but considerably different, as could be expected, in terms of the frequency of travelling together with others (e.g., more often escorted by a parent). Zwerts and Wets [8] found using cluster analysis evidence of a strong difference in travel behaviour between primary and secondary school children in the Belgium context. Stefan and Hunt [9] described results of a comprehensive analysis of activity patterns of children including both activity generation, time use and trip choice facets in the Calgary and Alberta regions in Canada. They also found that children's travel behaviour is characterized by the facts that (i) they often travel together with others, but that this tendency gradually decreases with age and (ii) becomes increasingly more similar to travel behaviour patterns of adults. School is the most important purpose of travelling. They found that children use an active mode of travelling more frequently compared to young adults (age 18-22 years). In weekends, children often engage in leisure activities together with the family and hence passenger in a vehicle appears to be an important transport mode of travelling. Yarlagadda and Srinivasan [10] focused specifically on school-travel behaviour of children and related influences on activities of parents. They estimated an econometric model of simultaneous mode and escorting person choice for travel to and from school based on travel survey data from the San Francisco Bay area. They found that socio-economic characteristics of children, such as age, gender and ethnicity, and employment and work flexibility characteristics of parents have strong influences on mode choice. Copperman and Bhat [11] described an exploratory analysis of the time use of children and several other facets of activities of children. They found strong effects of age on activity choice as well as day of week (weekday and weekend days) and time of day. Furthermore, they found a relatively high fraction of joint activity participation with individuals who are not family members and single-stop tours. Sener and Bhat [12] focused 
on the social context of children's discretionary activities in terms of accompanying persons involved in children's activities. Using the MDCEV methodology, they analyzed time investment of children in activities classified in terms of combinations of activity type and accompanying person. Estimation results support the hypothesis that social context, defined in that way, is an important factor in activity participation of children.

\section{Data}

The MON data represent the latest large-scale, nation-wide trip survey in the Netherlands. MON involves continuous data collection about mobility of the Dutch population. The survey includes a questionnaire and a trip-diary. All members of the household complete a questionnaire about their personal characteristics and fill out a travel diary for a designated day that is the same for all members of a household. Since children are included from the youngest age on and coverage is complete, the MON dataset is particularly suited to analyze activity participation and travel behaviour of children as well as interdependencies between activity-travel schedules between children and adults in the household. The data set includes 116 variables relating to 29,221 households, 66,482 persons and 206,499 trips. The following groups of variables are included: household and personal characteristics; spatial characteristics of the household's location (e.g., province, urban density); person-day travel characteristics (e.g., number of trips conducted); trip characteristics (e.g., main transport mode) and trip-stage characteristics (e.g., travel distance, transport mode).

\section{Basic results}

Usually, children are defined as those persons in a household that are 17 years or younger of age. Given our focus here, the way we operationally define 'child' differs somewhat. Our definition is tailored to a current practice of activity based models or, at least Albatross, to exclusively focus on the activity schedules of socalled household heads. Children in a household are defined as those persons who are not a household head (according to this definition) and of a younger generation (a larger age difference than roughly 18 years with a household head) than the household head. Defined in this way a child could be older than 17 years of age. For example, a young adult still living with his or her parents is identified as a child in the analyses reported in this study. In total, the data includes the activity patterns of 29,606 children, 6,553 of these persons are 18 years or older $(22 \%)$.

One of the key choice facets of activity-based analysis concerns activity participation, reflecting the number and kind of activities conducted. Table 1 describes activity participation by age group focusing exclusively on out-ofhome activities. Activities are broken down into the categories, typically used in activity-based models. Table 1 demonstrates some interesting relationships between activity participation and age group. 
Table 1: $\quad$ Number of activities per capita per day by activity type and age.

\begin{tabular}{lccccc}
\hline & $\begin{array}{c}0-5 \\
\text { years }\end{array}$ & $\begin{array}{c}6-11 \\
\text { years }\end{array}$ & $\begin{array}{c}12-14 \\
\text { years }\end{array}$ & $\begin{array}{c}15-17 \\
\text { years }\end{array}$ & $\begin{array}{c}18+ \\
\text { years }\end{array}$ \\
\hline Work & 0 & 0 & 0.016 & 0.158 & 0.505 \\
School & 0.406 & 0.940 & 0.691 & 0.578 & 0.201 \\
Picking up/dropping & & & & & \\
off person & 0.210 & 0.036 & 0.021 & 0.014 & 0.036 \\
Shop one store & 0.240 & 0.121 & 0.124 & 0.116 & 0.158 \\
Shop multiple stores & 0.048 & 0.026 & 0.032 & 0.032 & 0.033 \\
Service & 0.047 & 0.028 & 0.039 & 0.036 & 0.050 \\
Social & 0.302 & 0.272 & 0.256 & 0.244 & 0.238 \\
Leisure & 0.196 & 0.367 & 0.348 & 0.329 & 0.279 \\
Touring & 0.106 & 0.100 & 0.080 & 0.073 & 0.063 \\
Other & 0 & 0 & 0.003 & 0.003 & 0.005 \\
\hline Total & 1.554 & 1.891 & 1.610 & 1.582 & 1.567 \\
\hline N persons & 7051 & 8741 & 3772 & 3489 & 6553 \\
\hline
\end{tabular}

First, as expected, participation in work activities starts at the age 15-17 and then rapidly increases to approximately an average of 0.51 work episodes per day at $18+$ years of age. At the younger ages, it probably reflects part-time jobs to earn a little bit of pocket money or vacation jobs. Second, the number of school activities per capita per day first increases and then systematically decreases. The jump from 0.406 to 0.94 from $0-5$ years to $6-11$ years probably reflects the fact that the youngest children stay over at school for lunch while this is not necessarily the case for the next age group. In fact, traditionally, children tend to have lunch at home. However, recently, elementary schools by law have to offer the option to stay over for lunch at school to facilitate double-earner households. Beyond 12 years of age, the number of school activities decreases quickly, reflecting the fact that children at high school tend to stay over for lunch, but maybe also the high drop-out rates in the Netherlands, especially at lower levels of professional education. Thirdly, the average number of daily single-store shopping activities is higher for the very young children. It shows that they join (one of) their parents for grocery shopping. Once the children go to school the engagement in this type of shopping behaviour stabilizes but picks up slightly again at the age of 18 and older. Shopping at multiple stores in contrast is almost age-invariant for children older than 6 . The number of service activities is also highest for the youngest group, lowest for the 6-11 age group, and then slowly increases with increasing age.

Table 1 also shows information about the daily number of social, leisure and touring activities. The number of social activities and touring systematically decreases with increasing age. It suggests that children join their parents less frequently with increasing age. Moreover, with school and/or work becoming more important, the average number of social activities is reduced. A similar 


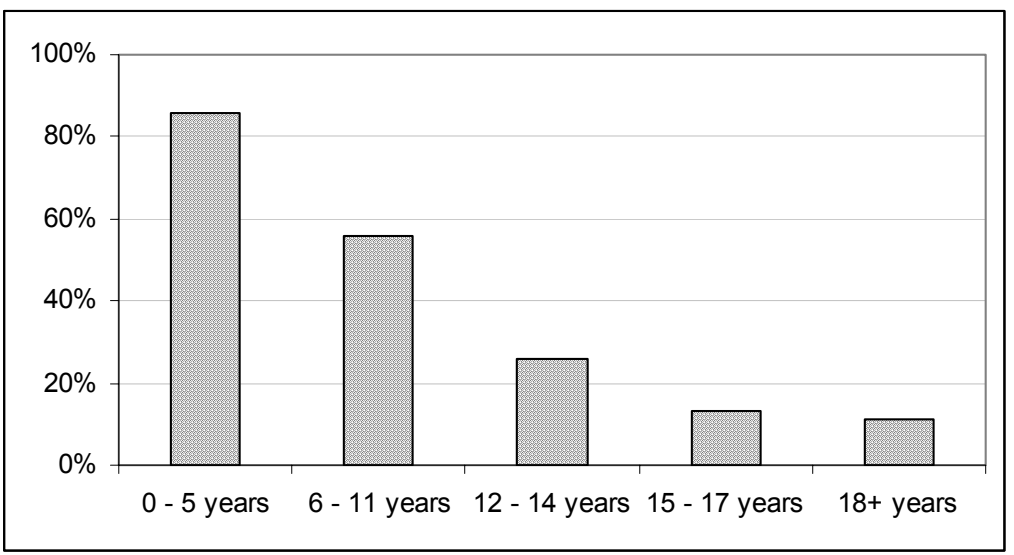

Figure 1: $\quad$ Percentage of children's activities accompanied to an older person in the household by age.

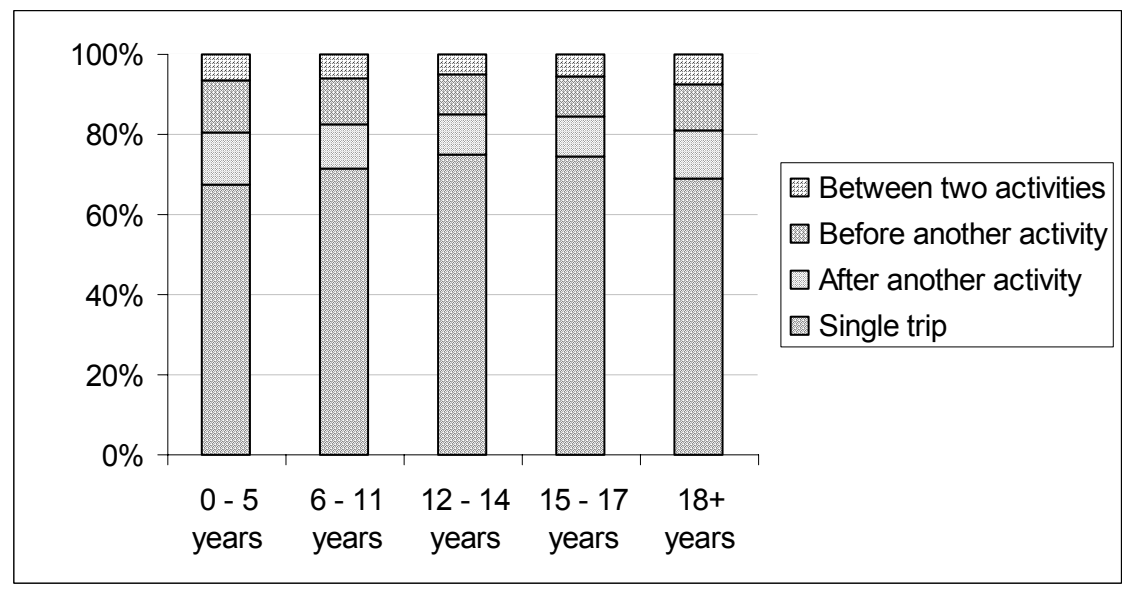

Figure 2: Children's relative frequency distribution of activities across tripstop type by age.

pattern is observed for leisure activities, except that persons of the youngest age group are less involved in this activity type.

Figure 1 shows for each age category the percentage of out-of-home activities where the children are accompanied by an older member of the family (of the same household). Clearly, this percentage shows a declining trend with increasing age.

Figure 2 displays the relative distribution of activities according to type of trip stop by age. It shows that the percentage of single trips increases with increasing age, until the age of 18 when the percentage of multi-stop trips increases. As found in previous research, it suggests that the travel behaviour of children 
becomes more similar to that of adults with increasing age. As shown in Figure 3 , not only is the percentage of single trips changing, but the action space of children is also increasing with increasing age, as one would expect. While a substantial percentage of trips at the youngest age take place in the immediate neighbourhood, the percentage is readily reduced with increasing age. Figure 4 provides evidence that the percentage of activities conducted at home is highest for the 0-5 age group, lowest for the 6-11 age group and then systematically increases with increasing age.

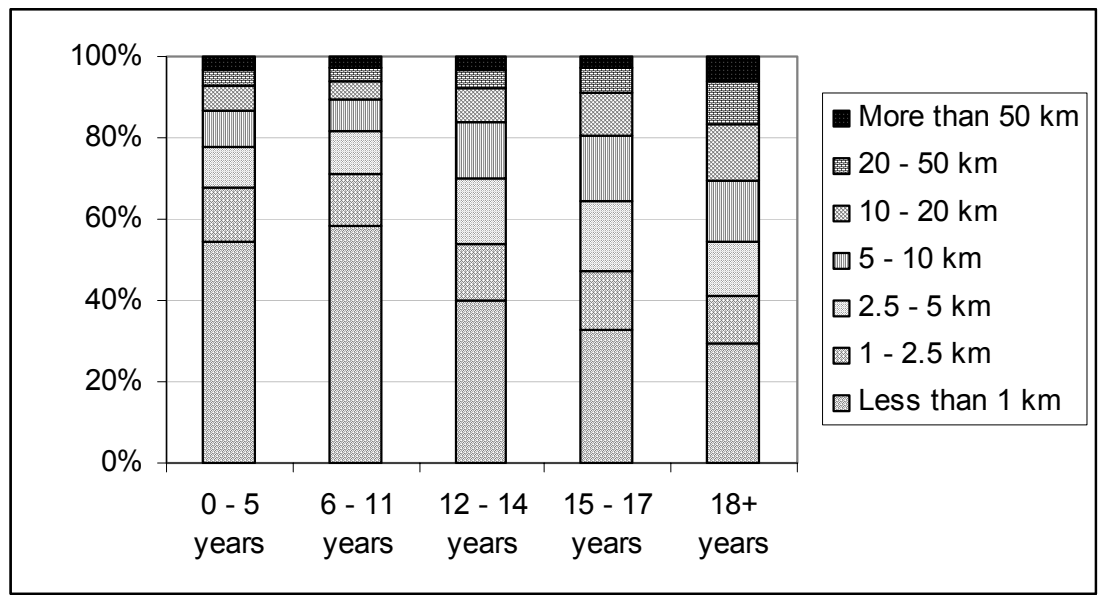

Figure 3: Children's relative frequency distribution of activities across travel distance by age.

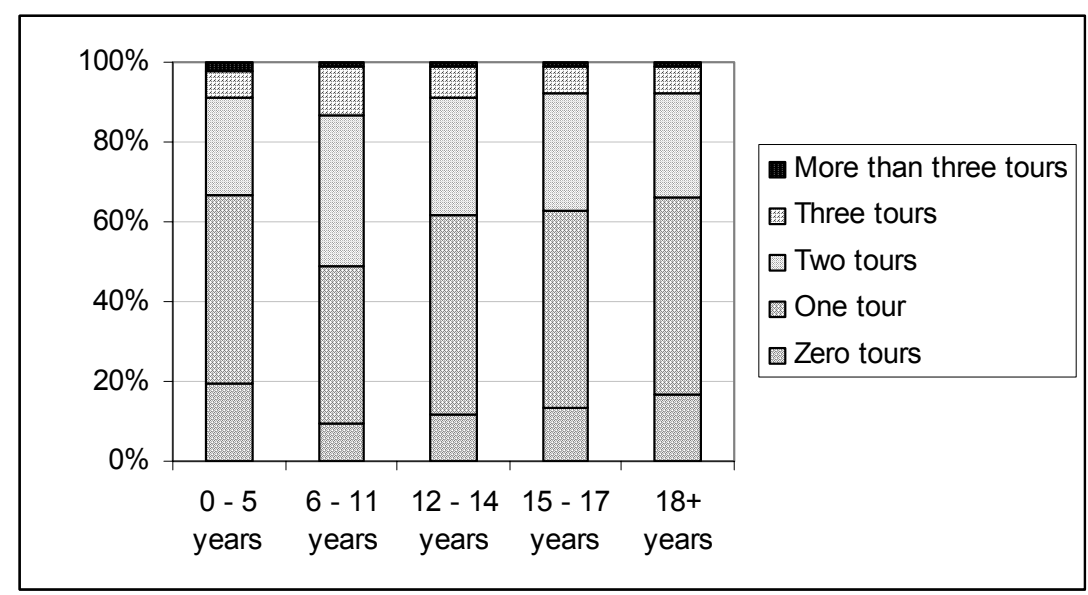

Figure 4: Children's relative frequency distribution of days across number of tours by age. 


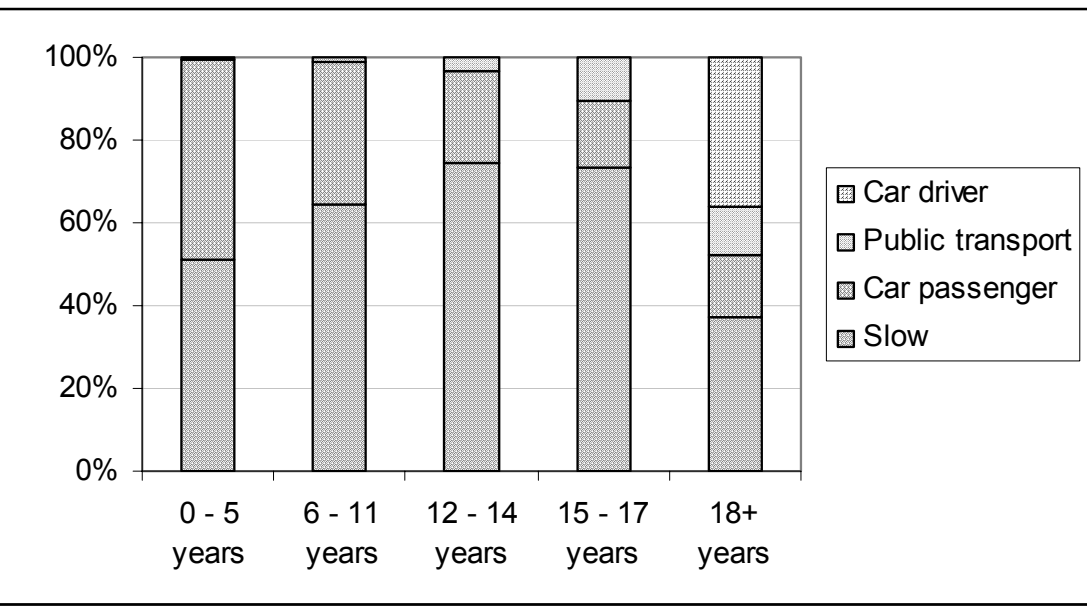

Figure 5: Children's relative frequency distribution of tours across transport mode by age.

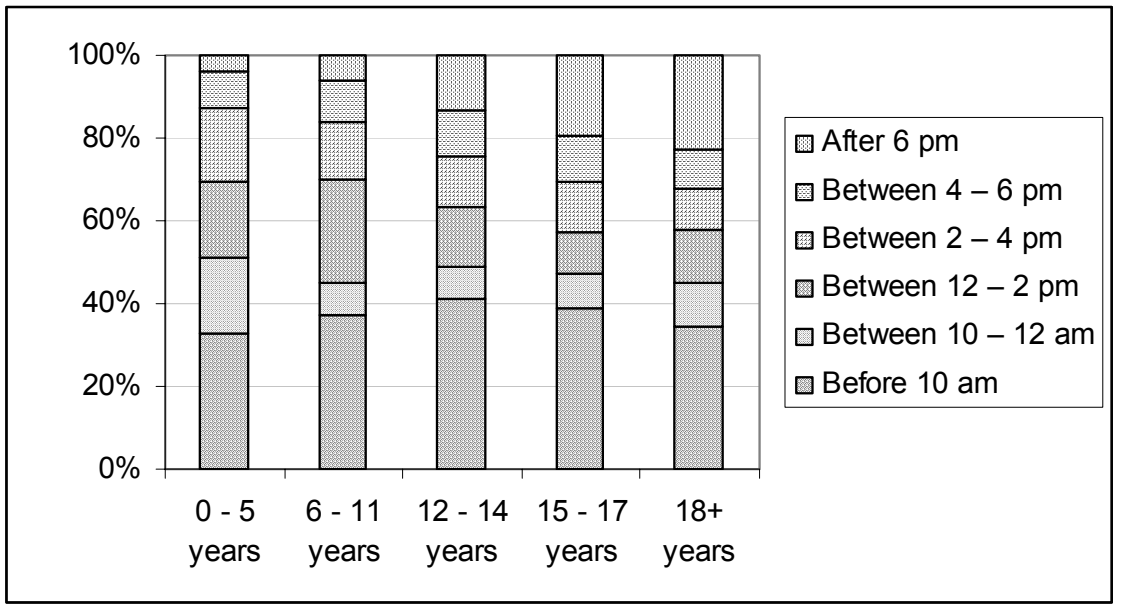

Figure 6: Children's relative frequency distribution of activities across start times by age.

Figure 5 gives an overview of the frequency distribution of transport modes for tours. It shows that the variation in transport modes increases with increasing age. Especially the share of public transport increases significantly from the 1517 years age group. Figure 6 portrays the distribution of start times of activities. The most interesting trend in this figure is that start times before 10am and after $6 \mathrm{pm}$ increase with increasing age. However, the share of start times before 10am for the 18+ age group is slightly smaller than the share for the 16-17 age group. Figure 7 provides information about the duration of activities. Once children go 


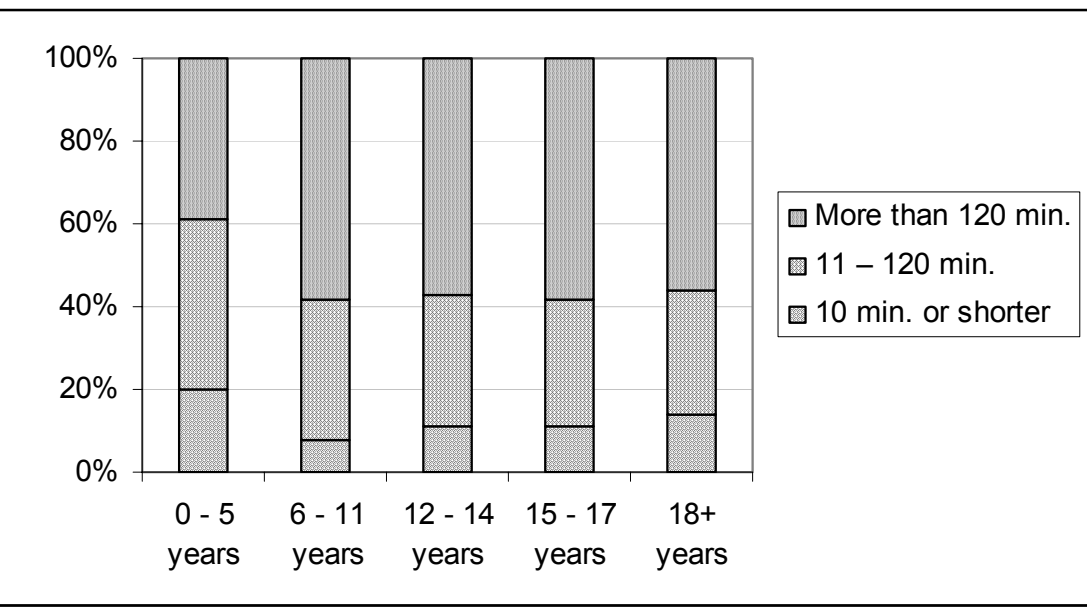

Figure 7: Children's relative frequency distribution of activities across duration classes by age

to elementary school the share of activities of long duration (more than 2 hours) rapidly increases and then stays more or less constant.

Finally, Table 2 shows the probability that one of the parents is at home if a child is at home. Selected are households with children younger than 12 years of age. Someone is considered at home in an episode if he or she is at least for part of the period at home. It shows this conditional probability is very high, especially in the evening and early morning. It is lowest for early afternoon.

Table 2: Probability that one of the parents is at home a-priori and conditional upon that child being at home.

\begin{tabular}{lccc}
\hline Episode & Conditional & A-priori & Ratio \\
\hline $8-10 \mathrm{am}$ & 0.965 & 0.929 & 1.039 \\
$10-12 \mathrm{am}$ & 0.931 & 0.776 & 1.200 \\
$12-2 \mathrm{pm}$ & 0.927 & 0.808 & 1.147 \\
$2-4 \mathrm{pm}$ & 0.912 & 0.799 & 1.141 \\
$4-6 \mathrm{pm}$ & 0.975 & 0.908 & 1.074 \\
$6-8 \mathrm{pm}$ & 0.989 & 0.958 & 1.032 \\
\hline
\end{tabular}

\section{Children vs. household heads}

To assess impacts of activity schedules of children on travel demands in a (national) population, a series of indicators of activity-travel patterns were compared between household heads and children. If there would be no significant differences, the effort of developing special models for children would not be worthwhile. If on the other hand there would be significant 
differences, it seems paramount to develop models for children to simulate the behaviour of an entire population.

Results indicate that there are significant differences in activity-travel behaviour of household heads and children for virtually all indicators. The most important exceptions are the number of activities during the weekend and Monday/Friday, the number of tours and related ratios and travel times by public transport. The first exception suggests that the behaviour of children over the weekend is related to the behaviour of household heads. Similarly, the results regarding number of tours and ratios have been found previously for other sociodemograhic groups and suggest there is some limit to the mental efforts in organising activities in terms of tours, which seems independent not only of socio-demographics but also of age (as defined in this analysis).

The average number of activities for children is smaller than for household heads, except for work/school and leisure and recreational activities. This difference is also observed for the days of the week. Although the absolute difference is high for Saturdays, it is not significant, which may be due to a higher variation in activity participation. As for duration class, children conduct more activities of longer duration, whereas the share of activities of smaller duration is significantly higher for household heads. The number of activities by start time is higher for children during lunch hour and in the early morning; for all other time slots it is higher for household heads. Children are more involved in single trips, whereas trip-chaining is more important for household heads. As expected, children on average conduct activities more often in their home zone and by other modes than car.

\section{Conclusions and discussion}

Traditional activity-based models of transport demand do not systematically incorporate the travel behaviour of children. Either children are not included at all, or they are partly included in the sense that some models simulate and predict travel party. The question then becomes whether this practice is good enough or that the recently appearing stream of research on travel behaviour of children should be more fully developed.

This paper was based on a very large dataset, collected in the Netherlands that systematically collected travel information of all persons in the household. Based on a descriptive analysis, several conclusions may be drawn. First, the activitytravel behaviour of children significantly differentiates from the behaviour of household heads. Children tend to participate in fewer activities, conduct these closer at home and less by car. Secondly, with increasing age and less dependency on parents, the activity-travel patterns of children become more similar to those of household heads, although participation in leisure activities remains higher. Corresponding start times also differ.

Because the key facets of their activity-travel patterns differ, it seems paramount to develop activity-based models of activity-travel behaviour of children. By doing so, one will capture more variability in behaviour than by focusing on travel party only. Given the evidence we obtained it is not sufficient 
to model the behaviour of children independently or as a separate layer. The interdependency between the activity-travel patterns of children and part of the pattern of household heads seem strong. Any model of children activity-travel patterns should therefore capture this interdependency.

\section{References}

[1] Bowman, J.L. and M.E. Ben-Akiva (2001). Activity-based disaggregate travel demand model system with activity schedules. Transportation Research A, 35, 1-28.

[2] Bradley, M., P. Vovsha (2005). A model for joint choice of daily activity pattern types of household members, Proceedings 84th TRB Annual Meeting, Washington, D.C.

[3] Bhat, C.R. and S.K. Singh (2000). A comprehensive daily activity-travel generation model system for workers. Transportation Research A, 34, 122.

[4] Pendyala, R.M., R. Kitamura, A. Kikuchi, T. Yamamoto and S. Fujii (2005). Famos, Proceedings 84th TRB Annual Meeting, Washington, D.C.

[5] Arentze, T.A. and H.J.P. Timmermans (2004). A learning-based transportation oriented simulation system, Transportation Research B, 38, 613-633.

[6] Roorda, M. E.J. Miller and K. Nurul Habib (2007). Validation of TASHA: A 24-hour activity scheduling microsimulation model, In: Proceedings 86th TRB Annual Meeting. (CD-Rom).

[7] McDonald, N.C. (2007). Children's travel patterns, Proceedings of the $86^{\text {th }}$ Transportation Research Board Annual Meeting (CD-Rom).

[8] Zwerts, E., G. Wets (2006). Children's travel behavior: a world of difference, Proceedings $85^{\text {th }}$ TRB Annual Meeting (CD-Rom).

[9] Stefan, K.J. and J.D. Hunt (2006). Age-based analysis of travel by children in Calgary, Canada, Proceedings of the $86^{\text {th }}$ Transportation Research Board Annual Meeting (CD-Rom).

[10] Yarlagadda1, A. K., S. Srinisavan (2008) Modeling Children's school travel mode and parental escort decisions. Transportation, 35, 201-218.

[11] Copperman, R.B., and C.R. Bhat (2007). An exploratory analysis of children's daily time-use and activity patterns using the child development supplement (cds) to the us panel study of income dynamics (PSID), Proceedings of the $87^{\text {th }}$ TRB Annual Meeting (CD-Rom).

[12] Sener, I.N., and C.R. Bhat (2007). An analysis of the social context of children's discretionary activity participation, Proceedings of the $87^{\text {th }}$ Transportation Research Board Annual Meeting (CD-Rom). 